\title{
A Research on Service Recognition
}

\author{
Shuliang Wang ${ }^{1}$, Jingru Tian ${ }^{1}$, Shanshan Zou ${ }^{2}$ \\ ${ }^{1}$ International School of Software, Wuhan University, Wuhan, China; ${ }^{2}$ International School of Software, Wuhan University, Wuhan, \\ China; ${ }^{3}$ Economics and Management School of Wuhan University, Wuhan, China. \\ Email: slwang2005@gmail.com, tianjingru2010@163.com
}

Received December $4^{\text {th }}$, 2010; revised January $19^{\text {th }}, 2011$; accepted January $23^{\text {rd }}, 2011$.

\begin{abstract}
Service exists in the service provider and the service receiver. They can produce the contractual relationship which is value and trust mutually. People can obtain the different intension of service with different knowledge background and technique. In this paper, service is recognized in the views of 12 levels. Through the description and analysis of these 12 levels, the method for existing services is summarized. Thereby the important impact on service science is elaborated in the modern economy.
\end{abstract}

Keywords: Service Recognition, Service Views, Service Analysis

\section{Introduction}

In the 21st century, the knowledge is taken as the foundation of information society. Similar to the technology to make the significance of economical, service is the soul of knowledge economy. The concept of service is defined as "The application of scientific, management, and engineering disciplines to tasks that one organization beneficially performs for and with another" in the modern economy [1], whereas the traditional service is described just as "Deed, act, or performance” [2].

More than 50 years ago, information technology made a tremendous development. Take this opportunity, computer science separated from electronic engineering and mathematics, and became an independent discipline. Referring to the computer science, service science also has the possibility to establish an independent discipline because of service economy appearance. And it will bring us many new challenges and opportunities.

In 2002, Almaden Service Research leading by Spohrer established, the first IBM Research group completely dedicated to understanding service innovations from a sociotechnical systems perspective, including enterprise transformation and industry evolution. Then on the "Architecture of on demand business” summit in May, 2004, the word of "service science" is finally officially raised as a new academic discipline [1].

In Maglio and Spohrer 2008, service science is "combines organization and human understanding with business and technological understanding to categorize and explain the many types of service systems that exist as well as how service systems interact and evolve to co-create value." They also commanded that the resources transfer and sharing within and among service systems is the centre of the service science.

This paper focuses on the service recognition to facilitate the understanding of service science. The rest of the paper is organized as follows. The analysis of service is stated in Section 2. Section 3 presents the 12 levels of service recognition and a brief description and analysis for each level is concluded. Finally, there is a summary in Section 4.

\section{Service Analysis}

The service exists in the service provider and the service receiver. They can produce the contractual relationship which is value and trust mutually. Distinguishing from the products of manufacturing and product purely process of product manufacturing, the services have the onstage and the backstage activities, both of them can create the values. In the industrialization degree less development stage, many services have not been independent from the traditional industry, are only take a part of the traditional industry as internal activity in the circulation, by no means servicing activities content. At present, the service expresses many new characteristics. They show as the knowledge and the technical density degree has enhanced, and the service market and the service providers to assume globalized unceasingly. These new characteristics, enable the service economy develop rapidly globally, also actuated the service and the industrial 
transformation, the request service industry breakthrough serves the commodity or serves the visible limit, realizes the service innovation.

\section{Service Views}

The service has abundant intension and extension, the goal lies in satisfies the association or individual some kind of need and by enhances its degree of satisfaction. When we understanding nature, human and society's service, based on the different knowledge background, or the different person based on the same knowledge background, according to the goal request which assigns, uses the different computing technique, refer to the different understanding level, the understanding factor and the reference standard, may obtain the different intension of service.

\subsection{Service Input}

Serves come from the nature, human and society's association or the individual demand. This kind of demand has the general character, also has the individuality, what but are more individuality demand. Along with information technology's development, when services input, except primary need, also increased personalization parameter. From the different angle and the different dimension, may give the service the different category (Table 1, [3]).

\subsection{Service Output}

"The service is the user received explicit and implicit benefits of a complete combination through the relevant facilities services of medium [4]." The service output is one "service package", not only includes the pure service, but also includes the service medium and so on a series of visible and the invisible gain combination. Obviously, the service output is different with the manufacture output. The manufacture output is the visible product which one kind is clear may result.

\subsection{Service Switching Process}

Service is the process to meet user needs. Service is to understand the needs of users, to take action to meet their needs, and ultimately win the customer satisfaction of a complete process. This process is invisible, basically cannot be touched, but the process itself contains the user's participation.

\subsection{Service Standard}

The ISO 9000 standards state that "Service is to meet the needs of users in contact with the users, the service provider's activities and results of the activities." W3C (World Wide Web Consortium, the World Wide Web alliance) defines service as: "The service provider completes a group of work, to serve the final outcome which the entire customer needs. The final outcome will usually cause the entire customer's condition to change, but possibly will also cause the provider changing their condition, or both sides will both have the change.”

\subsection{Composition Factor of Service}

Services include 4 kind of factors: support services facilities (to make possible the production of services), composition of products (services components), center benefits (service center), and fringe benefits (the expectations of services purchaser). Regarding for these four kinds of factors, service firms consider it to be service package, the customer regard them as a whole system, and producers use them as a system which can provide services with customer's expect.

\subsection{Service Product Configuration}

Service is one special product. The service is "a combination of entities and intangible". Any one service is not completely invisible, but an "entity" and "intangible" mixture of two parts (Figure 1, Liu, Du, 2008). Service invisible and product visible forms the sharp comparison, namely the former's intangibility and the latter's palpability. Product is the result of various factors' combination. Product mostly with palpable content is called the visible product; product mostly with intangible content is called immaterial product, namely service. In service, materiality part is easy to uniform and quantitative evaluation. But non-materiality part is difficult to uniform and quantitative evaluation. In most cases, the tangible products

Table 1. Service category.

\begin{tabular}{llll}
\hline Category Methods & Hill (1977) & Lovelock (1983) & Cunningham (2004) \\
\hline Angle & Supply-Oriented & Supply-Oriented & Demand-Oriented \\
Category & Single Categories & Combination Categories & Integration Categories \\
Dimension & 1.service object & 1.properties of service behavior & 1.individuation and standardization \\
& 2.state durability & 2.relationship between supplier & 2. object relativity \\
& 3.effect reversibility & and customer & \\
4.effect corporality & 3. customized degree and demand & \\
or spirituality & sense & \\
& & 4. properties of supply & \\
& & 5.service delivery method & \\
\hline
\end{tabular}




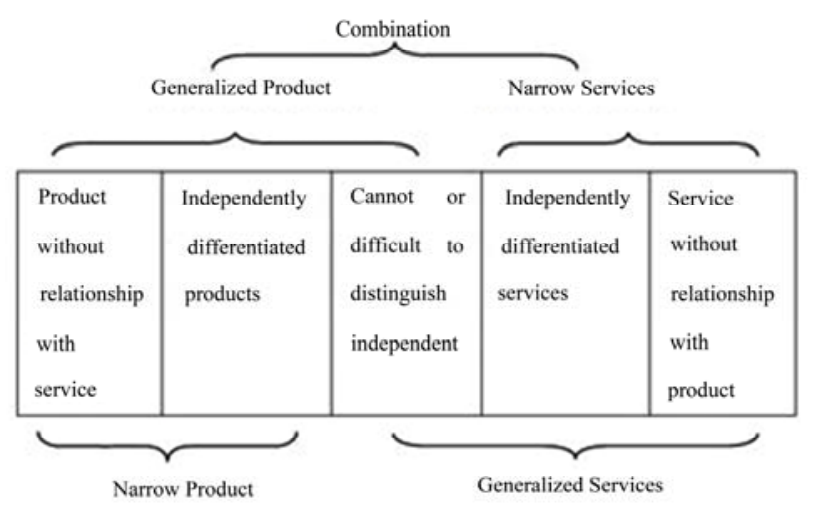

Figure 1. Definition service and product by specificity.

and intangible products cannot be completely separated. People were given a specific product or service is often tangible products and intangible products complexly [5].

\subsection{Service Characteristics}

Service characteristics concludes: service invisible, the production and the expense indivisibility, the service non-storability, the service heterogeneity, customer's participation in service process, does not involve transfer of ownership, etc. Modern service has a high level of integration capability and comprehensive professional outsourcing capabilities. Mature professional segments and special sharing capabilities are two key concepts of modern services. For example, there is competition among banks, but the settlement center can be outsourced to the same company.

\subsection{Service in the Role of Society and Economics}

First of all, services can reduce the space between producers and consumers, realize all logistics, information flow and capital flow transmission reasonable and promote knowledge and technical dissemination. Then the service also infiltrate in every chain such as physical goods production, distribution and consumption, and play a promotion role of realize the value and use value of physical goods. Moreover, the service can develop the physical commodity the value to increase its added value, enhances consumer's effectiveness, meets the consumer need well [6].

\subsection{Enterprise Service Bus}

Gartner believes that the Enterprise Service Bus (ESB) is a new structure with developing Web services, messaging middleware, intelligent routing and transmission, EBS is a central components of the flowing of software services and application integration. The service realize communication through routing, addressing and protocol conversion, use authorization, authentication and identification to assure security, process message with trans- formation, the media and certification, ensure service quality through affair distributed, use logs, measurement, monitoring, error processing and metadata to implement management.

\subsection{Service Developing Process}

Service is always exists, and the service complexity and integration become higher. An object, has the use value first, enters into the trading system for the exchange as goods. When goods move from the traders to customers, there are communications between people because of the value of the goods, or other things transmission, and the commercial contacts and relationships amount these communications is called service. At present, the increasing scale of services and the increasingly networked can be used in more areas of information delivery services or goods, the increasing number of transactions to accommodate the same time, getting higher and higher level of integration of services [7].

\subsection{Service Development Trend}

Provide a more professional or more efficient and cost-effective service is a common trend in the regional business [8]. According to the investigation, 92.1\% enterprise chooses "to provide a better service", 61.5\% enterprise chooses "to provide more professional, more efficient and more cost-effective service", $30.6 \%$ enterprise chooses "to move up to provide comprehensive services”. The eastern area and western area's government select significant increasing service-related operation in business in the next five years. It is much positive than the Northeast area and the middle area, reflected the fastest and the slowest economic development in regions with service-related business has a large demand. For the industry public services, the needs are significant in every different area, requiring a corresponding increase in personnel and material inputs.

\subsection{Service Mechanism}

E-commerce service mechanism mainly has $\mathrm{B}$ to $\mathrm{B}$ (Business to Business, enterprise serves other enterprise's demand through vertical gateway or level gateway, vertical gateway provides product or service to sole industrial type, level gateway provide multi-domains service), $\mathrm{B}$ to $\mathrm{C}$ (Business to Client, enterprise take user's demand as service target), $\mathrm{C}$ to $\mathrm{C}$ (Client to Client), $\mathrm{C}$ to $\mathrm{B}$ (Client to Business), B to $G$ (Business to Government, enterprise is committed to meet the needs of the government and other enterprises) and so on. E-government's service mechanism mainly has $G$ to $G$ (Government to Government, including electronic transfer of documents, e-justice file sharing, financial management, etc.), $G$ to B (Government to Business, including electronic procure- 
ment and tendering, electronic license processing, information resources services, etc.), G to C (Government to Citizens, including social insurance network services, transportation management services, residents e-Tax), IEE (Internal Efficiency and Effectiveness, internal government e-management improving efficiency and effectiveness, including electronic personnel management, records management, transaction management, etc.). An enterprise can serve both B to B and B to $G$ at the same time, many enterprises can be combined to provide adequate services using of collective strength to compete. Correspondingly, the enterprise and the enterprise may manage the product through the network (e.g. Digital China provide IT products through the "e-bridge" Web site for agents) or the service (e.g. Alibaba provides information services to enterprises with product sales and procurement business), the enterprise and the user can also manage the product (e.g. Joyo provide users with books, CDs and other products) or the service (e.g. EACHNET provide users with the auction and other business information services, Our game website to provide entertainment services for individual consumers). Excavation and cultivation in the use of the Internet user to maintain relations with existing customers in the process of increasing the value of services increases, service-based service capabilities pilot policy attracts more and more users. For example, Sina Website provides news, E-mail, advertising, messaging, games and other services for businesses or individuals, and China ICBC E-Bank provide financial services for businesses or individuals online.

\section{Conclusions}

This paper gives a view of 12 levels of service recognition so that we can understand the service science more clearly. The development of services is to maintain and enhance the market competitiveness of the needs. It is a necessary requirement for the metabolism of the service portfolio and also an effective means to mobilize idle capacity. Furthermore, it helps businesses offset the sea- sonal fluctuations in demand for services, helps businesses spread business risks, and it is the opportunities for enterprise to explore new market. Therefore, service enterprises should be developed new services suitable for market through a variety of ways within its capacity.

\section{Acknowledgements}

This paper is supported by National 973 (2006CB701305, 2007CB310804), National Natural Science Fund of China (60743001), Best National Thesis Fund (2005047), and Natural Science Fund of Hubei Province (CDB132).

\section{REFERENCES}

[1] J. Spohrer and P. P. Maglio, "The Emergence of Service Science: Toward Systematic Service Innovations to Accelerate Co-Creation of Value,” IBM Almaden Research Center, 2008.

[2] L. L. Berry, "Services Marketing Is Different," Business, Vol. 30, May-June 1980, pp. 24-29.

[3] Z. Y. Liu and S. F. Du, "Service Science Management and Engineering: A Rising Area,” Management Paper, Vol. 5, No. 4, 2008, pp. 607-615.

[4] J. Spohrer and D. Riecken, "Special Issue: Services Science," Communications of the ACM, Vol. 49, No. 7, July 2006, pp. 30-87. doi:10.1145/1139922.1139944

[5] C. H. Lovelock, "Classifying Services to Gain Strategic Marketing Insight: The Diversity of Service Sector Makes It Difficult to Come up with Managerially Useful Generalizations Concerning Marketing Practice in Service Organizations,” Journal of Marketing, Vol. 47, No. 3, 1983, pp. 9-20. doi:10.2307/1251193

[6] J. Gershuny and I. Miles, "The New Service Economy," London: Pinter, 1983.

[7] H. Chesbrough and J. Spohrer, "A Research Manifesto for Services Science,” Communications of the ACM, Vol. 49, No. 7, July 2006, pp. 35-40. doi:10.1145/1139922.1139945

[8] K. Hidaka, "Trends in Services Sciences in Japan and Abroad," Quarterly Review, Vol. 19, No. 4, April 2006, pp. 35-40. 